\title{
Correlation and Path Coefficient Analysis of Some Exotic Early Maturing Rice (Oryza sativa L.) Lines
}

\author{
Md. Manik Sarker, Lutful Hassan, Mirza Mofazzal Islam ${ }^{1}$, Md. Mamunur Rashid ${ }^{2}$ \\ and Shahjahan Seraj
}

Department of Genetics and Plant Breeding, Faculty of Agriculture, Bangladesh Agricultural University, Mymensingh.

${ }^{1}$ Biotechnology Division, Bangladesh Institute of Nuclear Agriculture, Mymensingh.

${ }^{2}$ Farm Management Division, Bangladesh Rice Research Institute, Gazipur, Bangladesh.

Corresponding author: kbdmanik@bau.edu.bd

\begin{abstract}
Correlation and path coefficient analyses of thirty two (32) exotic early maturing rice (Oryza sativa L.) lines were evaluated through their yield and yield contributing characters. Almost all the lines exhibited significance difference for different characters. The results indicated that days to $50 \%$ flowering $(0.42 *)$, days to maturity $\left(0.35^{*}\right)$, total tillers hill ${ }^{-1}\left(0.71^{* *}\right)$, effective tillers hill $^{-1}(0.82 * *)$ had positive and significant association with yield plant ${ }^{-1}$ for phenotypic correlation coefficient; whereas, unfilled grains panicle ${ }^{-1}\left(-0.19^{*}\right)$ had significantly negative correlation with yield. For phenotypic correlation coefficient, the days to $50 \%$ flowering $(0.50 *)$, days to maturity $(0.39 *)$, total tillers hill ${ }^{-1}\left(0.80^{* *}\right)$, effective tillers hill $^{-1}\left(0.88^{* *}\right)$ showed positive and significant association with yield plant ${ }^{-1}$, on the other hand unfilled grains panicle $\left(-0.19^{*}\right)$ had significantly negative correlation with yield. Path analysis revealed that days to maturity $\left(0.87^{* *}\right)$, total number of tillers hill ${ }^{-1}(0.25 * *)$, effective number of tillers hill $^{-1}\left(0.48^{* *}\right)$, panicle length $\left(0.68^{* *}\right)$ and number of filled grain panicle $^{-1}(1.29 * *)$ had positive direct effects on yield plant ${ }^{-1}$. Results suggest days to maturity, total number of tillers hill ${ }^{-1}$, and effective number of tillers hill ${ }^{-1}$ may be used as reliable criteria for improving yield of early maturing rice.
\end{abstract}

Key words: Correlation, Path Analysis, Early Maturing, Rice and Yield

\section{Introduction}

Rice (Oryza sativa L.) is one of the most leading food crops in the world and staple food for over $60 \%$ of the world's population, mostly in Asia. Bangladesh is an agro-based country and predominately rice based. Bangladesh earns about $18.7 \%$ of her GDP from agriculture (Economic Review, 2013). The world is facing many different security problems in the $21^{\text {st }}$ century: food is one of them. Within 2025 the demand of rice globally will be 880 million ton which is $70 \%$ more than present production (IRRI, 2010). The current level of rice grain production in Bangladesh is 18.04 million tons, total demand is 35.3 million ton and cropping intensity is $183 \%$ (BBS, 2012). Therefore, to fill up the gap between production and demand, we need to increase cropping intensity nearly $300 \%$. Short duration rice is an important aspect to increase cropping intensity. Correlation coefficient determines the simple relations among the traits. It does not determine always decisive result about determination of plant selection criteria (Cakmakci et al. 1998). Path coefficient analysis as to correlation coefficient gives more detailed information on the relations, so it is commonly used by plant breeders to determine yield and yield contributing characters (Board et al. 1997, Williams et al. 1990).The objective of the study was to study the correlation coefficient and path coefficient analysis of early maturing rice lines for evolving yield and yield contributing characters. 


\section{Materials and Methods}

The study was conducted from July 2012 to November 2012 in the experimental field of Bangladesh Institute of Nuclear Agriculture (BINA), Mymensingh-2202. Geographically the experimental area is located at $24^{0} 75 \mathrm{~N}$ latitude and $90^{0} 5 \mathrm{E}$ longitudes at the elevation of $18 \mathrm{~m}$ above the sea level.

\section{Experimental materials}

Thirty one early maturing rice lines along with check variety Binadhan-7 were used for the experiments. Mutant variety, Binadhan-7 is the popular early maturing variety. The seeds of the rice lines were collected from International Network for Genetic Evaluation of Rice (INGER), International Rice Research Institute (IRRI), Philippines.

Table 1. List of experimental materials

\begin{tabular}{lll|lll}
\hline Sl No & Lines Name & Origin & Sl No & Lines Name & Origin \\
\hline 1 & IR 79246-105-2-2-4 & IRRI & 17 & BP 1018F-BB8-13-BB4 & INDONESIA \\
2 & IR 73718-26-1-2-5 & IRRI & 18 & IR 79525-20-2-2-2 & IRRI \\
3 & BP 10620F-BB4-13-BB8 & INDONESIA & 19 & IR 80285-34-3-3-2 & IRRI \\
4 & IR 79538-1-1-1-1 & IRRI & 20 & CT 18173-1-9-1-3-6-M & CIAT \\
5 & IR 76494-28-1-2-2 & IRRI & 21 & BP 10620F-BB4-2-BB4 & INDONESIA \\
6 & YN 2883-12-2-1 & MYANMAR & 22 & PSB RC 64 & INDIA \\
7 & AD 02207 & INDIA & 23 & IR 08N261 & IRRI \\
8 & BP 10620F-BB4-8-BB8 & INDONESIA & 24 & RATNAGIRI 2 & INDIA \\
9 & C1-4-11-7P-2P-1P & CIAT & 25 & MTU-1113 & INDIA \\
10 & IR 79201-49-1-1-1 & IRRI & 26 & KARJAT 5 & INDIA \\
11 & BP 10620F-BB4-12-BB8 & INDONESIA & 27 & KHAZAR & IRAN \\
12 & IR 82489-594-3-2-2 & IRRI & 28 & IR 59552-21-3-2-2 & IRRI \\
13 & CT 18509-10-6-1VI-2 & CIAT & 29 & C 2-9-9-2P-1P-3P & CIAT \\
14 & IR 74052-153-5-3-1-3 & IRRI & 30 & IR 39809-26-3-3 & IRRI \\
15 & PSD RC 2 & IRRI & 31 & CT 18148-11-1-1-1-1-M & CIAT \\
16 & IR 08N293 & IRRI & 32 & Binadhan-7 & BINA \\
\hline
\end{tabular}

\section{Experimental Design}

The experiment was laid out in a Randomized Complete Block Design (RCBD) with three replications. The row to row and plant to plant distances were $20 \mathrm{~cm}$ and $15 \mathrm{~cm}$, respectively. The recommended fertilizer dose was 220 (Kg/ha) Urea, $100(\mathrm{Kg} / \mathrm{ha}) \mathrm{TSP}$ and 70 (Kg/ha) MOP.

\section{Collection of data}

The following data Plant height $(\mathrm{cm})$, days to $50 \%$ flowering, days to maturity, total tillers and effective tillers hill ${ }^{-1}$, filled and unfilled grains panicle ${ }^{-1}, 1000$ seed weight $(\mathrm{g})$, yield plant ${ }^{-1}(\mathrm{~g})$ were collected from randomly selected of 5 plants from each unit plot.

\section{Statistical analysis}

Analysis of variance was performed using the plant breeding statistical program (PLBSTAT, Version $2 \mathrm{~N}$, Utz 2007) with the following model: $\mathrm{Y}_{\mathrm{ij}}=\mathrm{g}_{\mathrm{i}}+\mathrm{r}_{\mathrm{j}}+\varepsilon_{\mathrm{ij}}$

Where, $Y_{i j}=$ observation of genotype $i$ in replication $j ; g_{i}=$ effects of genotype $I ; r_{j}=$ effects of replication $\mathrm{j}$ and $\varepsilon_{\mathrm{ij}}=$ the residual error of genotype $\mathrm{i}$ in replicate $\mathrm{j}$.

\section{Formula used for estimation of genetic and phenotypic parameters}

The genotypic and phenotypic correlations were estimation by the formula suggested by Miller et al. (1985). 
Phenotypic correlation, $\quad \mathrm{r}_{\mathrm{p} 1.2}=\frac{\operatorname{CoV} \cdot p_{1.2}}{\sqrt{\delta^{2} p_{1} \times \delta^{2} p_{2}}}$

Where, CoV. $\mathrm{p}_{1.2}=$ phenotypic covariance between the trait $\mathrm{x}_{1}$ and $\mathrm{x}_{2} ; \delta^{2} \mathrm{p}_{1}=$ phenotypic variance of the trait $\mathrm{x}_{1}$ and $\delta^{2} \mathrm{p}_{2}=$ phenotypic variance of the trait $\mathrm{x}_{2}$.

Genotypic correlation, $\quad \mathrm{r}_{\mathrm{g} 1.2}=\frac{\operatorname{CoV} \cdot g_{1.2}}{\sqrt{\delta^{2} g_{1} \times \delta^{2} g_{2}}}$

Where, CoV.g. $\mathrm{g}_{1.2}=$ genotypic covariance between the trait $\mathrm{x}_{1}$ and $\mathrm{x}_{2} ; \delta^{2} \mathrm{~g}_{1}=$ genotypic variance of the trait $\mathrm{x}_{1}$ and $\delta^{2} \mathrm{~g}_{2}=$ genotypic variance of the trait $\mathrm{x}_{2}$.

Direct and indirect path coefficients were calculated as described by Lynch \& Walsh (1998).

$$
r_{y i}=P_{y i}+\sum_{\substack{i^{\prime}=1 \\ i^{\prime} \neq i}}^{k} r_{i i^{\prime}} P_{y i^{\prime}} \quad \text { for } i \neq 1
$$

Where: $r_{y i}$ is the correlation coefficient between the $i$-th causal variable $\left(X_{i}\right)$ and effect variable $(y)$, $r_{i i^{I}}$ is the correlation coefficient between the $i$-th and $i^{\prime}$-th causal variables, $\boldsymbol{P}_{\boldsymbol{y} i \bar{i}}$ is the path coefficient (direct effect) of the $i$-th causal variable $\left(X_{i}\right),{ }^{i i^{I}} P_{y i^{r}}$ is the indirect effect of the $i$-th causal variable via the $i^{\prime}$-th causal variable.

\section{Results and Discussion}

\section{Variations and performance of the genotypes}

The analyses of variance of 10 important quantitative characters for different genotypes are shown in Table 2. Analysis of variance resulted in significant variations among the genotypes for the following characters: plant height, days to $50 \%$ flowering, days to maturity, total number of tillershill ${ }^{-1}$, effective tillers hill $^{-1}$, panicle length (cm), filled grains panicle ${ }^{-1}$, number of unfilled grains panicle ${ }^{-1}$, yield plant ${ }^{1}$ (g) and 1000 seed weight (Table 2). These results indicated that there was a genotypic variation among the genotypes for the characters.

Table 2. Mean squares analysis for morphological traits in 32 rice genotypes

\begin{tabular}{llllllllllll}
\hline Characters & df & DF & DM & PH & PL & TT & ET & FG & UG & SWT & Y/P \\
\hline Genotypes & 31 & $79.7^{* *}$ & $183.9 * *$ & $129 * *$ & $4.73^{* *}$ & $17.8^{* *}$ & $13.1^{* *}$ & $2996.1 * *$ & $761.4^{* *}$ & $17.3^{* *}$ & $15.3^{* *}$ \\
Replication & 2 & 2.67 & 3.04 & 10.8 & 6.63 & 23.5 & 19.1 & 1137 & 576.3 & 0.03 & 4.95 \\
Error & 62 & 7.74 & 4.30 & 10.6 & 1.60 & 6.69 & 3.97 & 447.2 & 143.8 & 0.01 & 1.85 \\
\hline
\end{tabular}

* indicates significant at $0.05 * *$ indicates significant at 0.01 probability

$\mathrm{DM}=$ Days to $50 \%$ flowering, DM=Days to maturity, $\mathrm{PH}=$ Plant height $(\mathrm{cm}), \mathrm{TT}=$ Total number of tillershill ${ }^{-1}$, ET=Effective number of tillers hill ${ }^{-1}$, PL=Panicle length $(\mathrm{cm}), F G=F i l l e d$ grains panicle ${ }^{-1}$, UG=Unfilled grains panicle $1, \mathrm{SWT}=1000$ seed weight $(\mathrm{g}), \mathrm{Y} / \mathrm{P}=\mathrm{Yield} \mathrm{plant}^{-1}(\mathrm{~g})$

\section{Correlation coefficient}

Result of correlation co-efficient at phenotypic and genotypic levels indicated that grains yield plant ${ }^{-}$ ${ }^{1}$ had non-significant positive association with days to $50 \%$ flowering, days to maturity, total no. of tillers, effective of number of tillers hill ${ }^{-1}$, number of filled grains panicle ${ }^{-1}$, number of unfilled grains panicle ${ }^{-1}$ and weight of 1000 seeds (Table 3). An non-significant positive correlation of grains yield with 50\% flowering and weight of 1000 seeds were also observed by Das et al. (1992) and Choudhury et al. (1998). 
Days to $50 \%$ flowering had significant positive correlation with 1000 seed weight and yield plant ${ }^{-1}$ but non-significant positive correlation with days to maturity, plant height, total number of effective tillers hill $^{-1}$, number of effective tillers hill ${ }^{-1}$, number of filled grains panicle ${ }^{-1}$ and number of unfilled grains panicle $^{-1}$ (Table 3). But the result of correlation between days to $50 \%$ flowering and weight of 1000 seeds were contradictory to the findings of Dhanraj et al. (1989) where there two characters were negatively correlated but Chookar et al.(1994) found a significant positive correlation between these characters. Days to 50\% flowering had significant positive correlation with weight of 1000 seeds and yield plant ${ }^{-1}$. But significant negative correlation accounted with unfilled grains panicle ${ }^{-1}$ at the both level (genotypic and phenotypic level). Days to maturity had significant positive correlation with yield plant ${ }^{-1}$ but significant negative correlation with 1000 seed weight. Plant height had significant positive association with panicle length and filled grains panicle ${ }^{-1}$, and negative correlation with total number of, number of effective tillers hill $^{-1}$, 1000 seed weight and yield plant ${ }^{-1}$. Number of effective tillers hill $^{-1}$ showed positive significant association with number of filled grains panicle ${ }^{-1}$ and yield plant $^{-1}$. Number of filled grains panicle ${ }^{-1}$ showed positive and significant association with yieldplant ${ }^{-1}$. This finding was partially in agreement with the results of Chaudhury et al. (1998) and Debi et al. (1997). Total number of tillers hill ${ }^{-1}$ showed significant positive correlation with Effective number of tillers hill $^{-1}$ and yield plant ${ }^{-1}$. The results of the present study suggested that days to $50 \%$ flowering plant height, days to maturity, total number of tillers hill ${ }^{-1}$, number of effective tillers hill ${ }^{-1}$, number of filled grains panicle ${ }^{-1}$ and yield plant ${ }^{-1}$ are the most important characters. Therefore, selection based on these characters may bring out desired improvement towards enhancing the grains yield in rice.

Table 3. Estimates of phenotypic correlation coefficients between yield and yield component characters

\begin{tabular}{lccccccccc}
\hline Characters & DM & PH & TT & EF & PL & FG & UG & SWT & Y/P \\
\hline DF & 0.04 & 0.18 & 0.24 & 0.02 & -0.29 & 0.31 & $-0.38^{*}$ & $0.42^{*}$ & $0.42^{*}$ \\
DM & & -0.09 & 0.31 & 0.33 & -0.08 & 0.06 & 0.16 & $-0.47^{* *}$ & $0.35^{*}$ \\
PH & & & -0.09 & -0.03 & $0.60^{* *}$ & $0.36^{*}$ & 0.20 & -0.23 & -0.13 \\
TT & & & & $0.94^{* *}$ & 0.01 & $0.35^{*}$ & -0.10 & -0.03 & $0.71^{* *}$ \\
ET & & & & & 0.04 & $0.35^{*}$ & 0.04 & -0.04 & $0.82^{* *}$ \\
PL & & & & & & 0.28 & 0.17 & -0.28 & 0.05 \\
FG & & & & & & & -0.20 & -0.08 & 0.14 \\
UG & & & & & & & -0.25 & $-0.19^{*}$ \\
SWT & & & & & & & -0.13 \\
\hline$*$ Fignificant at 1\%
\end{tabular}

** $=$ Significant at $1 \%$ level of probability $*=$ Significant at $5 \%$ level of probability

$\mathrm{DM}=$ Days to $50 \%$ flowering, DM=Days to maturity, $\mathrm{PH}=\mathrm{Plant}$ height $(\mathrm{cm}), \mathrm{TT}=$ Total number of tillershill ${ }^{-1}$,

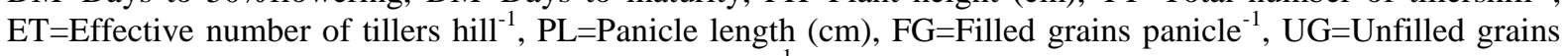
panicle $1, \mathrm{SWT}=1000$ seed weight $(\mathrm{g}), \mathrm{Y} / \mathrm{P}=\mathrm{Yield} \mathrm{plant}^{-1}(\mathrm{~g})$

Table 4. Estimates of genotypic correlation coefficients between yield and yield component characters

\begin{tabular}{lccccccccc}
\hline Characters & DM & PH & TT & EF & PL & FG & UG & SWT & Y/P \\
\hline DF & 0.05 & 0.20 & 0.28 & 0.24 & -0.36 & 0.39 & $-0.41^{*}$ & $-0.48^{*}$ & $0.50^{*}$ \\
DM & & -0.10 & 0.39 & 0.43 & -0.09 & 0.09 & 0.19 & $-0.51^{* *}$ & $0.39^{*}$ \\
PL & & & -0.16 & -0.03 & $0.68^{* *}$ & $0.42^{*}$ & 0.24 & -0.28 & -0.19 \\
TT & & & & $0.99^{* *}$ & 0.08 & $0.39^{*}$ & -0.16 & -0.08 & $0.80^{* *}$ \\
ET & & & & & 0.08 & $0.38^{*}$ & 0.08 & -0.09 & $0.88^{* *}$ \\
PL & & & & & & 0.29 & 0.19 & -0.29 & 0.05 \\
FG & & & & & & -0.28 & -0.09 & 0.19 \\
UG & & & & & & -0.29 & $-0.21^{*}$ \\
SWT & & & & & & & & & -0.18 \\
\hline$*$ = Significant at 1\% level of probability * Significant at 5\% level of probability &
\end{tabular}


$\mathrm{DM}=$ Days to $50 \%$ flowering, DM=Days to maturity, $\mathrm{PH}=\mathrm{Plant}$ height $(\mathrm{cm}), \mathrm{TT}=$ Total number of tillershill $^{-1}$, $\mathrm{ET}=$ Effective number of tillers hill ${ }^{-1}, \mathrm{PL}=$ Panicle length $(\mathrm{cm}), \mathrm{FG}=$ Filled grains panicle ${ }^{-1}, \mathrm{UG}=\mathrm{Unfilled}_{\text {grains }}$ panicle 1 , SWT=1000 seed weight $(\mathrm{g}), \mathrm{Y} / \mathrm{P}=\mathrm{Yield}^{-1} \operatorname{lant}^{-1}(\mathrm{~g})$

\section{Path co-efficient analysis}

From the results of path analysis (Table 5), it was evident that direct effects contributed by days to maturity $(0.87)$, total number of tillers hill ${ }^{-1}(0.25)$, effective number of tillers hill ${ }^{-1}(0.48)$, panicle length $(0.68)$ and number of filled grains panicle ${ }^{-1}(1.29)$ were high indicating that among the component traits, these five characters contributed maximum for yield plant ${ }^{-1}$ (Table 5). The direct effects of days to maturity, effective number of tillers hill ${ }^{-1}$, number of filled grains panicle $^{-1}$ were higher than their respective correlation co-efficient but lower for plant height and number of tillers number of unfilled grains panicle ${ }^{-1}$. The indirect effects of the below some characters were less important.

Thus direct selections for these traits were effective Chaudhury and Das (1998) observed high positive direct effect of days to maturity towards grains yield. Liu et al. (2001) reported the highest positive direct effect of number of filled grains panicle ${ }^{-1}$ on yield plant ${ }^{-1}$ followed by 1000 grains weight and number of filled grains panicle ${ }^{-1}$. Chanbey and Singh (1994) observed maximum positive direct effect of number of effective tillers hill ${ }^{-1}$ followed by plant height and 1000 grains weight. Samonte et al. (1998) reported major influence number of filled grains panicle ${ }^{-1}$ on yield.

Although the character, days to $50 \%$ and days to maturity were positively correlated with yield but its direct effect on grains yield plant $^{-1}$ was negative. It indicated that this character influenced grains yield by its indirect positive effects through days to maturity, plant height, and number of unfilled grains panicle ${ }^{-1}$ and weight of 1000 seeds. Mehetre et al. (2003) reported negative direct effect of days to $50 \%$ flowering on grains yield. Plant height showed a low negative direct effect on grains yield plant ${ }^{-1}$ but the correlation co-efficient was significantly positive. Kumar et al. (2001) reported moderate direct effect of plant height to grains yield.

Table 5. Estimation of path analysis showing direct and indirect effect of traits on grain yield

\begin{tabular}{cccccccccc}
\hline Characters & DM & PH & TT & EF & PL & FG & UG & SWT & Y/P \\
\hline DF & $\mathbf{- 0 . 3 1}$ & -0.17 & -0.01 & 0.03 & -0.05 & -0.10 & 0.02 & -0.07 & -0.10 \\
DM & 0.49 & $\mathbf{0 . 8 7}$ & 0.82 & 0.02 & -0.07 & 0.53 & 0.01 & 0.04 & -0.25 \\
PL & -0.05 & -1.18 & $\mathbf{- 1 . 2 5}$ & -0.45 & -0.44 & -0.44 & -0.35 & -0.39 & -0.21 \\
TT & -0.02 & 0.06 & 0.09 & $\mathbf{0 . 2 5}$ & 0.02 & 0.01 & 0.04 & -0.05 & -0.09 \\
ET & 0.08 & -0.03 & 0.17 & 0.05 & $\mathbf{0 . 4 8}$ & -0.11 & -0.01 & -0.02 & -0.13 \\
PL & 0.21 & 0.42 & 0.24 & 0.03 & -0.16 & $\mathbf{0 . 6 8}$ & -0.17 & 0.29 & 0.24 \\
FG & -0.11 & 0.01 & 0.36 & 0.22 & -0.04 & -0.33 & $\mathbf{1 . 2 9}$ & 0.92 & 1.06 \\
UG & -0.10 & -0.02 & -0.13 & 0.09 & 0.01 & -0.18 & -0.31 & $\mathbf{- 0 . 4 3}$ & -0.06 \\
SWT & -0.19 & 0.16 & -0.06 & 0.22 & 0.16 & -0.20 & -0.47 & -0.08 & $\mathbf{- 0 . 5 7}$ \\
\hline
\end{tabular}

Bold figures indicate the direct effect, Residual effect $=0.204$

$\mathrm{DM}=$ Days to $50 \%$ flowering, DM=Days to maturity, $\mathrm{PH}=\mathrm{Plant}$ height $(\mathrm{cm})$, TT=Total number of tillershill ${ }^{-1}$, ET=Effective number of tillers hill ${ }^{-1}, \mathrm{PL}=$ Panicle length $(\mathrm{cm}), \mathrm{FG}=$ Filled grains panicle ${ }^{-1}, \mathrm{UG}=\mathrm{Unfilled}_{\text {grains }}$ panicle $1, \mathrm{SWT}=1000$ seed weight $(\mathrm{g}), \mathrm{Y} / \mathrm{P}=\mathrm{Yield} \mathrm{plant}^{-1}(\mathrm{~g})$

\section{Conclusion}

The performance of different exotic rice lines for grain yield and different yield contributing characters were evaluated. There were significant variations among the genotypes for the characters plant height, days to flowering, days to maturity, total tillers hill $^{-1}$, effective tillers hill ${ }^{-1}$, filled grains panicle $^{-1}$, panicle length, unfilled grains panicle ${ }^{-1}$, yield plant $^{-1}(\mathrm{~g})$ and 1000 seed weight. Days to 50\% 
flowering had significant positive correlation with 1000 seed weight and yield plant ${ }^{-1}$, and significant negative correlation with unfilled grains panicle ${ }^{-1}$ but non-significant positive correlation with days to maturity, plant height, total effective tillers hill ${ }^{-1}$, effective tillers hill ${ }^{-1}$ and filled grains panicle ${ }^{-1}$. From the results of path analysis it is evident that direct effects contributed by days to maturity, total number of tillers hill ${ }^{-1}$, effective number of tillers hill $^{-1}$, panicle length and number of filled grains panicle ${ }^{-1}$ an these five characters contributed maximum for yield plant ${ }^{-1}$.

\section{Acknowledgments}

This work was supported by International Network for Genetic Evaluation of Rice (INGER), International Rice Research Institute (IRRI), Philippines by providing rice seeds. We thank Dr. Shamsun Nahar Begum, Biotechnology Division, Bangladesh Institute of Nuclear Agriculture, Mymensingh, and Dr. Arif Hasan Khan Robin, Department of Genetics and Plant Breeding, Bangladesh Agricultural University, Mymensingh, for critiquing the manuscript.

\section{References}

BBS (Bangladesh Bureau of Statistics), 2012. Monthly Statistical Bulletin of Bangladesh. Stat. Div., Minst. Planning, Bangladesh Bur. Stat, Govt. People's Repub. Bangladesh, Dhaka. p. 182.

Board, J.E., Kang, M.S. and Harville, B.G. 1997. Path analyses indentify indirect selection criteria for yield of late planted Soybean. Crop Sci., 37: 879-884

Cakmakci, S., Unay, A. ad Acikgoz, E. 1998. An investigation on determination of characters regarding to seed and straw yield using different methods in common vetch. Turk. J. Agric. 22: $161-166$

Chaubey, P.K. and Singh, R.P. 1994. Genetic variability. Correlation and path analysis of yield components of rice. Madras Agril. J. 81(9): 468-470.

Chookar, S.K.; Marakar, R.V. and Siddiq, M.A. 1994.Genetic variability for grain yield and yield contributing characters in rice. J. Maharashtra Agril. Univ. 19(2): 236-238.

Choudhury, P.K.D. and Das, P.K. 1998. Genetic variability, correlation and path co-efficient analysis in deep water rice, Ann. Agril. Res. 19(2): 120-124.

Das, R.K., Islam, M.A., Howlader, M., Ebrahim, S.M., Ahmad, H.V. and Miah, N.M. 1992. Variability and genetic association in upland rice (Oryza sativa L.). Bangladesh J. Plant Breed. Genet. 5(1-2): 51-56.

Debi, B.R., Ray, P.K.S. and Howladar, M. 1997. Variability and genetic association in irrigated rice. Prog. Agric. 8(1/2): 165-168.

Dhanraj, A., Jagadish, C.A. and Upre-Vijay, B. 1989. Studies on character association in the F2 generation of ten selected crosses in rice. J. Res. APAU. 15(1): 64-65.

Economic Review of Bangladesh, 2013. Economic advisory subdivision, Economic Divi. , Ministry of planning, Govt. People's Republic of Bangladesh, Dhaka, p. 91.

IRRI (International Rice Research Institute), 2010. Annual Report for 2009. International Rice Research Institute, Los Banos, Laguna, Philippines. pp.179-181.

Kumar, R., Thakur, R., Mishra, S.B. and Singh, D.N. 2001. Variability studies in segregating population of rice (Oryza sativa L.). Annals Biol. 17(1): 43-45.

Liu, Wei., Shi,YanLi., Liu, W. and Shi, Y.L. 2001. Preliminary report on heterosis of japonica hybrid rice in Ningxia. Crop Ins. of Ningxia Aca. Agricultural- Forest. Science. Yongning 750105, Ningxia, China.

Lynch, M. and Walsh, B. 1998. Genetics and Analysis of Quantitative Traits. Sinauer Associates, Sunderland, MA.

Mehetre, R.N., Yadava, M.S. and Mohan, K.S. 2003. Genetic variation, character association and path analysis in rainfed upland rice. Indian. J. Dry land Agril. Res. Develop. 18 (2): 196-198. 
Millar C. K., Kralios F. A., Lux R. L. 1985. Correlation between refractory periods and activationrecovery intervals from electrograms: effects of rate and adrenergic interventions. Circulation, 72: 1372-1379.

Samonte, L., Singh, J. D. and Sachan, N. S. 1989. Inter character association and path analysis in paddy (Oryza sativa L.). Annals of Biology. 1.8(2):125-128.

Utz, H.F., 2007. PLABSTAT (Version 2N), a computer program for the computation of variances and covariances. Institute of Plant Breeding, Seed Science, and Population Genetics, University of Hohenheim, Stuttgart, Germany.

Williums, W.A., Jones, M.B. and Demment, M.W. 1990. A concise table for path analysis statistics. Agron. J., 82: 1022-1024.

\section{Citation for this Article:}

M. M. Sarkar, L. Hasan, M. M. Islam, M. M. Rashid and S. Seraj, 2014.Correlation and path coefficient analysis of some exotic early maturing rice (Oryza sativa L.) lines. Journal of Bioscience and Agriculture Research 01 (01): 01-07. 